\title{
ESTUDO DE ACESSIBILIDADE EM MONUMENTOS DE VALOR HISTÓRICO EM MARIANA, MINAS GERAIS.
}

\author{
PINTO, Maria Angélica V. ; RIBEIRO FILHO, Guido L.; MARIA, Thaís C.; FERREIRA, Franciele M.C.; SILVA, \\ Thiago, H. O.; MARIA, Robert C.. \\ Instituto Federal de Educação, Ciência e Tecnologia de Minas Gerais - IFMG \\ DOI:10.15628/diálogos.2018.6752
}

Artigo submetido em dez/2017 e aceito em jun/2018

\section{RESUMO}

Este artigo apresenta alguns dos resultados de um projeto de pesquisa de iniciação científica "Proposta de estudo de mobilidade urbana em monumentos de valor histórico e cultural na cidade de Congonhas, Minas Gerais" e pretende estudar a acessibilidade das cidades históricas de Ouro Preto, Congonhas e Mariana para adquirir conhecimentos sobre a problemática de acesso de pessoas de baixa mobilidade e aplicar lições aprendidas no desenvolvimento de uma proposta de soluções de acessibilidade aos monumentos históricos de Congonhas-MG. A metodologia utilizada é a realização de visitas técnicas às cidades envolvidas com registro fotográfico de campo, tabulação de dados e estudo de soluções para cada caso. 0 objetivo do artigo, além de divulgar os resultados da pesquisa realizada, é servir como referência para pesquisas correlatas.

PALAVRAS-CHAVE: Acessibilidade, Monumentos Históricos, Turismo.

\section{INTRODUÇÃO}

Mariana, primeira Vila, primeira capital e sede do primeiro bispado de Minas Gerais, guarda consigo parte da história da arquitetura brasileira.

Fundada a partir do descobrimento do ouro, às margens do Ribeirão Nossa Senhora do Carmo em 1696 pelos bandeirantes paulistas sob comando de Salvador Fernandes Furtado de Mendonça, a localidade deu origem ao arraial Nossa Senhora do Carmo, que logo se transformou em um dos principais fornecedores de ouro para Portugal, sendo elevada a Vila por D João V, o rei de Portugal em 1711 e seria a primeira Vila da Capitania de "São Paulo e Minas de Ouro" para tornar-se sua primeira capital, batizada com o nome de Mariana, em homenagem à rainha Maria Ana D'Austria, sua esposa. Devido à estreita relação da Igreja Católica com o Estado e o poder, transformou-se também no primeiro bispado da Capitania.

Primeiro conglomerado urbano planejado da capitania e um dos primeiros do Brasil tem 
valor histórico importante para a arquitetura nacional, o que motivou seu tombamento histórico em 1945, buscando a manutenção de suas características e preservação do patrimônio.

Segundo Camêllo (2016):

O Séc. XVIII fez de Minas o centro econômico e cultural da colônia. O ouro que exerceu tanta influência, inclusive na economia da Europa, foi o elemento propulsor do povoamento e da estruturação da Capitania de Minas Gerais. Além de gerar resultados materiais, produziu outros fatores que redundaram nas mais diferentes manifestações artístico-culturais, surgindo um Aleijadinho, um Athayde, um Lobo de Mesquita, escritores, eclesiásticos, monumentos religiosos e civis, tudo a construir um barroco genuinamente mineiro e um jeito próprio de ser, enfim a moldura de um panorama no qual se fermentava o sentimento de liberdade.

A realidade à época da construção dos monumentos históricos coloniais, pela precariedade das habitações, buscava a maior parte delas apenas abrigo e proteção, e os conglomerados urbanos possuíam as características semelhantes às adotadas nas demais cidades coloniais portuguesas, de habitações geminadas e ruas estreitas e buscava atender necessidades das oligarquias e dos que então ascendiam socialmente com a riqueza do ouro. Construções mais suntuosas eram reservadas ao clero, a prédios públicos, igrejas.

Atualmente o Brasil vem buscando a democratização do turismo para divulgação destas cidades históricas e mais recentemente, tentando viabilizar a inclusão social de pessoas com necessidades especiais, deparou-se com um problema não imaginado pelos arquitetos da época das construções coloniais: a acessibilidade (ABNT NBR 9050:2004).

Atendendo ao comando constitucional, foi editada, dentre outras, a Lei $n^{\circ} 10.098$, de 19 de dezembro de 2000, a qual estabeleceu normas gerais e critérios básicos para a promoção da acessibilidade das pessoas portadoras de deficiência ou com mobilidade reduzida, por meio da supressão de barreiras e obstáculos nas vias e espaços públicos, no mobiliário urbano, na construção e reforma de edifícios e nos meios de comunicação e transporte. (RULLI NETO, 2002).

Para Souza e Gitahy (2012) esta lei traz em seu texto definições importantes, como, por exemplo, a da própria acessibilidade, de barreiras arquitetônicas, elementos de urbanização e outras.

\section{FUNDAMENTAÇÃO TEÓRICA}

Temática ainda recente no país, a acessibilidade registra importante crescimento nas duas últimas décadas, quando assiste à disseminação de grupos, pesquisas e publicações, denotando o interesse de significativa parcela da comunidade científica por essa área (Villarouco, 2011).

Segundo Alves (2014) um espaço inclusivo vai para além da acessibilidade arquitetônica e 
inclui o acesso à informação e à participação na programação. Assim sendo, estas melhorias não estão apenas orientadas para as pessoas com deficiência, mas para todos (p. ex. crianças, mulheres grávidas, pessoas com língua materna diferente da do país em que se encontram, pessoas idosas, pessoas com doenças diversas).

A falta de acessibilidade aos monumentos históricos é um fator que dificulta o contato com a história e prejudica a democratização da cultura e da informação. Como garantir a estas pessoas o direito à cultura?

Segundo CADTEC09 (2014):

Para que haja acessibilidade do ambiente físico da cidade, é necessário eliminar barreiras e adotar o desenho universal, que significa projetar pensando em todos os usuários, inserindo soluções como guias rebaixadas e rampas nas travessias, substituindo degraus, calçadas com larguras adequadas para atender as pessoas com dificuldades de locomoção, tais como cadeirantes, carrinhos de bebes e outras restrições de mobilidade.

Segundo Ferreira, 2001 é necessário "garantir sua plena compreensão, preservando as edificações em sua autenticidade, mantendo características físicas, espaciais e também de caráter de obra de arte".

A cidade histórica pode ser definida como aquela portadora de um núcleo central ou centro histórico, compreendido como um espaço vivo, em constante transformação, no qual as marcas da passagem do tempo se fazem presentes em construções que expressam valores históricos e estéticos (JOKILEHTO, 2002).

Monumentos e sítios históricos são insubstituíveis e é necessário garantir sua preservação para futuras gerações, porém o acesso a esses espaços também é um direito de todos e essas barreiras dificultam o pleno acesso das pessoas não possibilitando que estas se tornem cidadãos no pleno gozo de seus direitos e deveres (Neves, 2010).

Jester e Park (1993) abordam que a autonomia e a acessibilidade física em propriedades históricas podem ser conseguidas com planejamento cuidadoso, consulta a especialistas e projeto sensível. Recomendam identificar e executar modificações de acessibilidade que protejam a integridade e o caráter histórico das propriedades a partir de três aspectos: rever o significado histórico da propriedade e identificar suas características; avaliar a propriedade existente e requerida ao nível da acessibilidade; avaliar opções de acessibilidade dentro de um contexto de preservação.

Vive-se num momento em que é necessário defender dois interesses legítimos e dicotômicos: Garantir o acesso a essas pessoas com as devidas modificações na arquitetura ou preservar o monumento histórico intacto para preservar a história. A partir desta discussão, origina-se o presente artigo, onde se busca alternativas para garantir o acesso universal a todos nas cidades 
históricas, porém preservando a arquitetura desses monumentos.

Esta discussão precisa evoluir. Não se deve permanecer na rigidez da preservação dos aspectos arquitetônicos originais da obra, bem como interceder nas obras que possuem centenas de anos de história, heroicamente ou por um golpe de sorte preservado até a data de hoje.

Estaria a solução para este problema em alternativas removíveis que assegurem acesso seguro e confortável de forma que seja reversível o aspecto original da obra a qualquer tempo sem realização de obras? Isso é possível? O trabalho realizado tem como objetivo fazer um levantamento da acessibilidade física sob a ótica do usuário nos bens tombados pelo IPHAN e pelo IEPHA da cidade de Congonhas e estabelecer intercâmbio com os escritórios do IPHAN, nas cidades de Mariana, Ouro Preto e Congonhas, com a colaboração de alunos bolsistas e alunos do Curso Técnico de Edificações do IFMG Campus Congonhas.

\section{METODOLOGIA - A VISITA TÉCNICA}

Realizou-se uma visita técnica com a finalidade pesquisar a acessibilidade a Monumentos Históricos e do seu entorno.

O desenvolvimento do projeto de pesquisa com os alunos bolsistas levou o grupo a conhecer o IPHAN, seu funcionamento e equipe técnica e arquivo de documentos históricos e realizar uma incursão na cidade de Mariana e alguns pontos turísticos de grande importância histórica com a contribuição de arquitetas do IPHAN, professores do IFMG e um guia turístico local.

Pretende-se aplicar os conhecimentos adquiridos durante a visita técnica a Mariana para o desenvolvimento do projeto de acessibilidade, já em andamento para a cidade de Congonhas.

A rota escolhida para o estudo de acessibilidade e mobilidade é o trajeto entre o escritório técnico do IPHAN, situado à Rua Direita e Praça Minas Gerais (Figura1).

A Praça Minas Gerais é formada pelos monumentos históricos da Igreja São Francisco de Assis, Figura 2; a Igreja de Nossa Senhora do Carmo, Figura 3; um pelourinho, Figura 1; que estão localizados em frente à antiga Casa de Câmara e Cadeia, Figura 4, atualmente a sede da Câmara Municipal de Mariana.

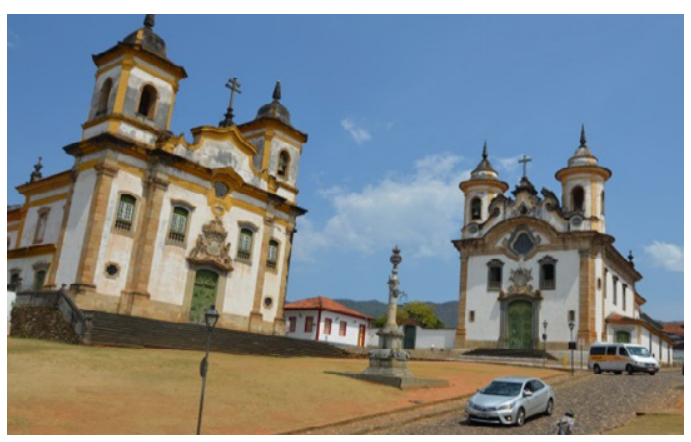

Figura 1 - Praça Minas Gerais Fonte: arquivo pessoal dos autores

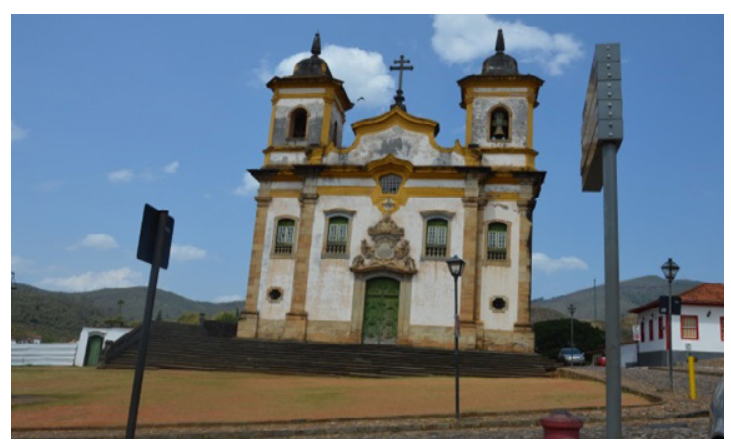

Figura 2 - Igreja São Francisco de Assis Fonte: arquivo pessoal dos autores 
ISSN - 2447-7869

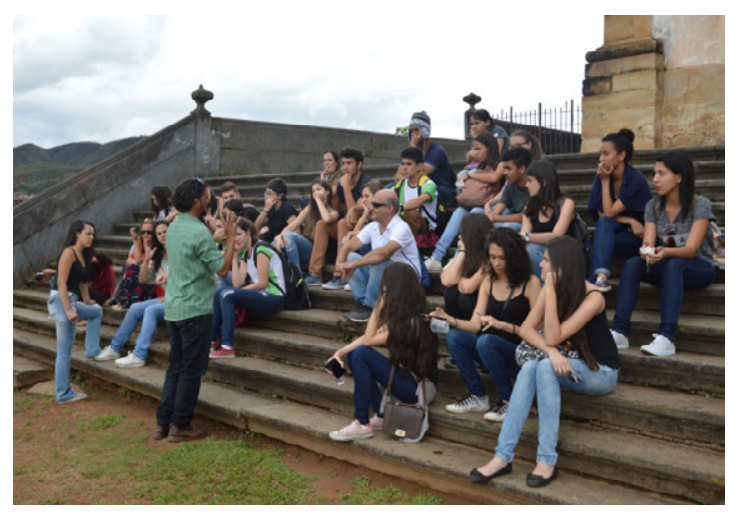

Figura 5 - Apresentação da Praça Minas Gerais aos alunos pelo guia de turismo. Fonte: arquivo pessoal dos autores

\section{Diálogos da Extensão}

REVISTA DA PRÓ-REITORIA DE EXTENSÃO DO IFRN

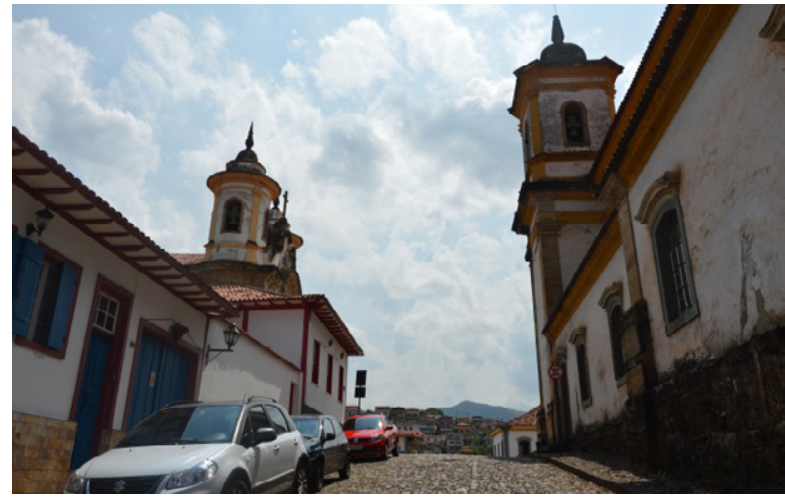

Figura 6 - Travessa São Francisco Fonte: arquivo pessoal dos autores

Após os estudos feitos na Praça Minas Gerais, os visitantes seguiram pela da Rua Dom Silvério até a Igreja de São Pedro dos Clérigos, passando pela Igreja Nossa Senhora do Carmo. (Figuras 7 e 8 ).

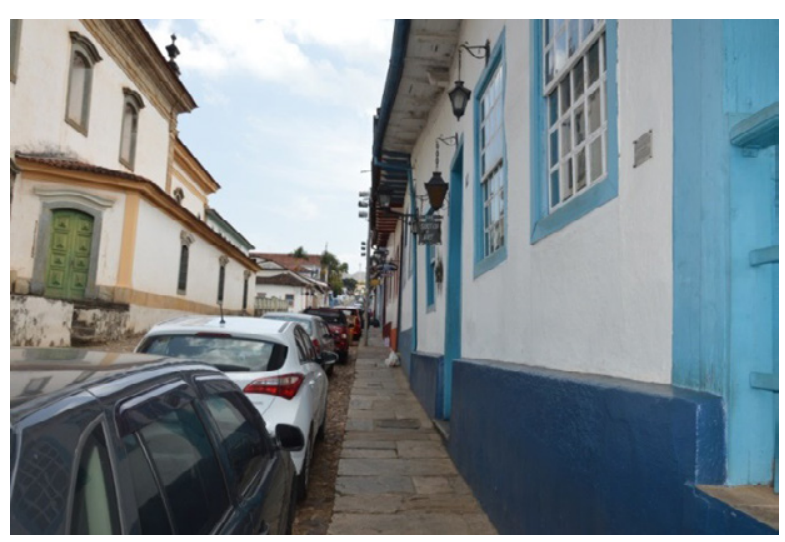

Figura 7 - Vista do passeio na Rua Dom Silvério Fonte: arquivo pessoal dos autores

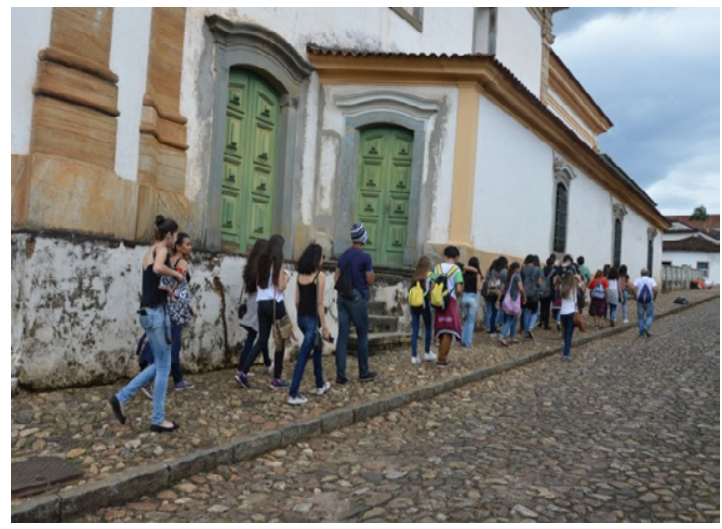

Figura 8 - Passeio na lateral da Igreja Nossa Senhora do Carmo

Fonte: arquivo pessoal dos autores

Na sequencia cruzou-se a Rua Silva Jardim (Figura 9), em direção à Igreja de São Pedro dos Clérigos (Figuras 10 e 11,13,14) passando pela residência do pintor sacro marianense Manuel da Costa Ataíde, um importante artista do Barroco-Rococó mineiro (Figura 12). 
ISSN - 2447-7869

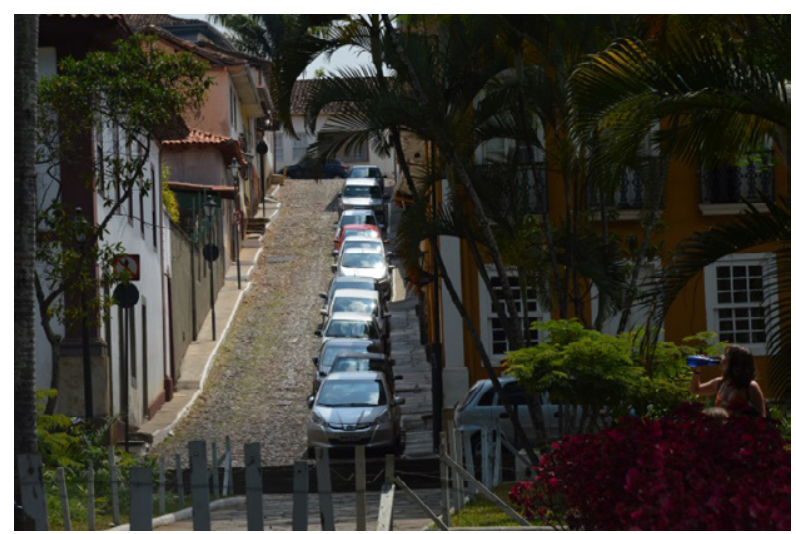

Figura 9 - Vista do passeio na Rua Silva Jardim Fonte: arquivo pessoal dos autores

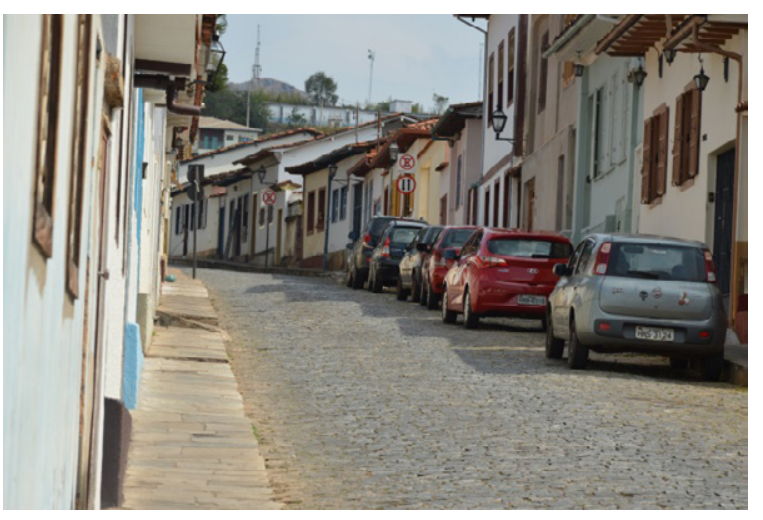

Figura 11 - Vista do passeio na Rua Dom Silvério Fonte: arquivo pessoal dos autores

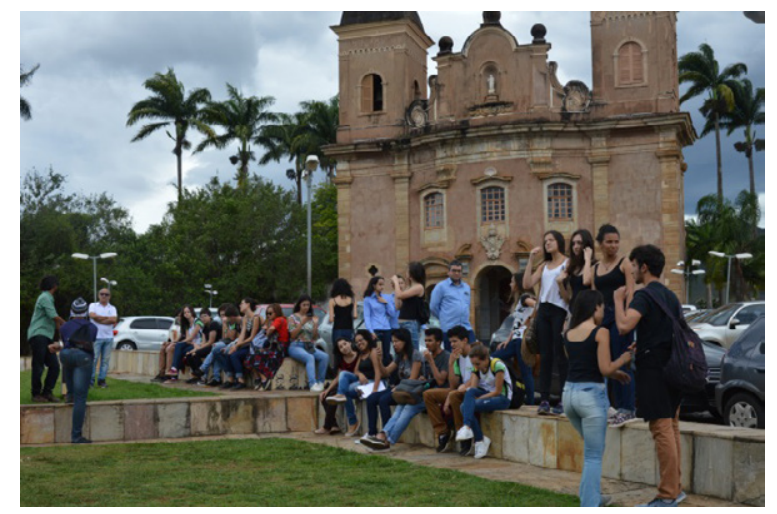

Figura 13 - Chegada dos alunos na Igreja São Pedro dos Clérigos

Fonte: arquivo pessoal dos autores

\section{Diálogos da Extensão}

REVISTA DA PRÓ-REITORIA DE EXTENSÃO DO IFRN

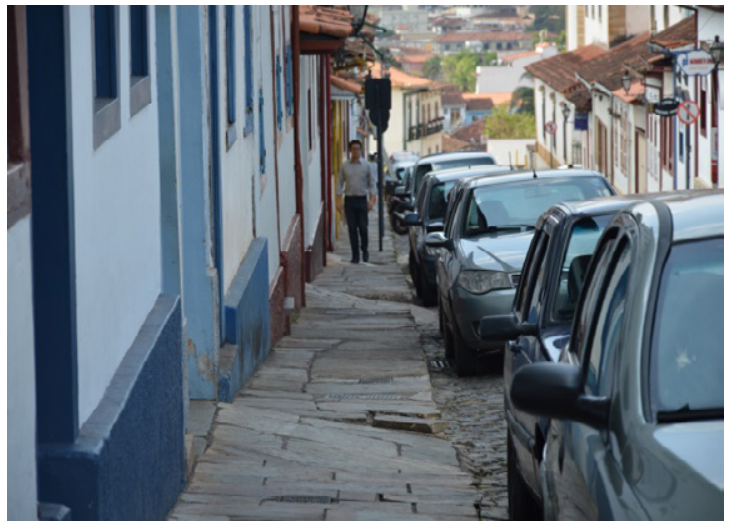

Figura 10 - Situação do passeio na Rua Dom Silvério Fonte: arquivo pessoal dos autores

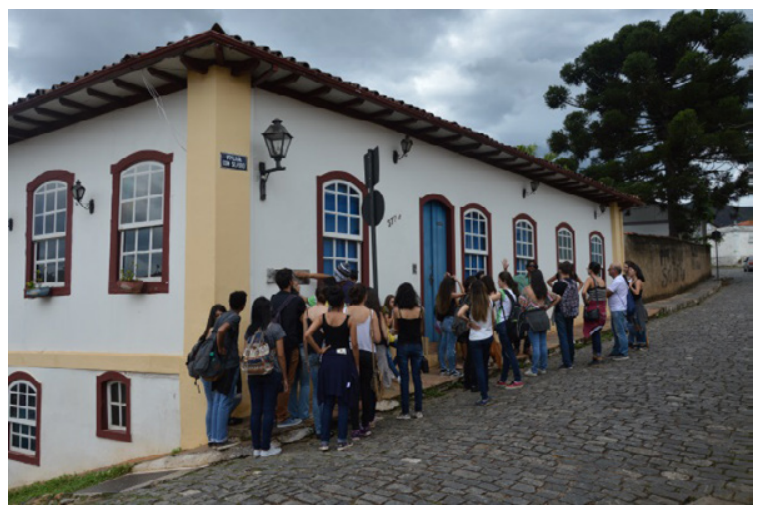

Figura 12 - Casa que morou o mestre Manuel da Costa Ataíde

Fonte: arquivo pessoal dos autores

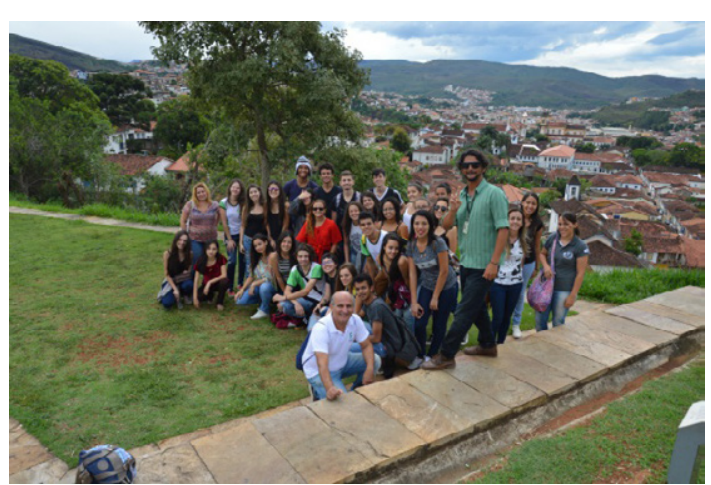

Figura 14 - Alunos e professores com o fundo da vista parcial de Mariana

Fonte: arquivo pessoal dos autores 


\section{CONCLUSÃO}

Este artigo levantou alguns aspectos para os pesquisadores (alunos e professores do Curso Técnico de edificações do IFMG Campus Congonhas) sobre as questões de acessibilidade a Monumentos Históricos e seu entorno.

Houve uma contribuição para os alunos e professores sobre as formas e alternativas utilizadas na preservação do patrimônio cultural da cidade de Mariana, a fim de aplicar os conhecimentos adquiridos na cidade de Congonhas, Minas Gerais, para o projeto de acessibilidade.

Verificações para estudo de soluções:

- Na Praça Minas Gerais o calçamento construído com seixos rolados prejudica o acesso aos monumentos a pessoas com baixa mobilidade.

- Monumentos com acesso apenas por escadarias, o que os torna inacessíveis a pessoas com baixa mobilidade.

- Na Igreja Nossa Senhora do Carmo, o passeio e ruas construídos em seixos rolados prejudicam a passagem de cadeiras de rodas e pessoas com deficiência visual.

- Na Rua Silva Jardim, os passeios são extremamente estreitos (cerca de $40 \mathrm{~cm}$ ) são de difícil tráfego até para pessoas com boa mobilidade. Inacessível para cadeiras de rodas.

- Na Rua Dom Silvério, as edificações alteram a configuração das calçadas para acesso de veículos às propriedades, cujo desnível para rampas não permite acesso de cadeiras de rodas.

- Placas de sinalização de trânsito, instaladas no eixo das estreitas calçadas impossibilitam o tráfego de pessoas com deficiência de mobilidade e deficiência visual, podendo causar acidentes.

\section{REFERÊNCIAS BIBLIOGRÁFICAS}

ALVES, F. " Regina Cohen, Cristiane Duarte, e Alice Brasileiro - Acessibilidade a Museus ", MIDAS [Online], 3 | 2014, posto online no dia 12 maio 2014, consultado no dia 10 julho 2018. URL : http://journals.openedition.org/midas/450.

ASSOCIAÇÃO BRASILEIRA DE NORMAS TÉCNICAS. Acessibilidade a edificações, mobiliário, espaços e equipamentos urbanos: NBR 9050. Rio de Janeiro: ABNT, 2004.

CADTEC09. Mobilidade e Acessibilidade Urbana em Centros Históricos. Organização de Sandra Bernardes Ribeiro. Brasília: IPHAN 2014. (Cadernos Técnicos; 9). 120 p.

CAMÊLLO, R.. Mariana assim nasceram as Minas Gerais: uma visão panorâmica da História. Belo Horizonte, Nitro, 2016. 232 p.

FERREIRA, O. L.. Patrimônio Cultural e Acessibilidade. As Intervenções do Programa Monumenta, 
de 2000 a 2005. Tese de doutorado. Programa de Pesquisa e Pós-Graduação. PPG/FAU. Faculdade de Arquitetura e Urbanismo, Universidade de Brasília, Brasília. 321 p.

JESTER, T. C; PARK, S. C. Making Historic Properties Acessible. Technical Preservation Services (TPS), Heritage Preservation Services Division, National Park Service, AIA, 1993.

JOKILETHO, Juka. Conceitos e ideias sobre conservação. In JOKILETHO, J. RT et all. Gestão do patrimônio cultural Integrado. Recife: Ed. Universitária da UFPE, 2002.

NEVES, J.B. Acessibilidade e preservação das cidades históricas: uma análise do município de Morretes. Monografia apresentada ao curso de Especialização em Serviço Social como requisito parcial para obtenção do título de Especialista em Serviço Social. Universidade Federal do Paraná.

RULLI NETO, Antonio. Direitos do portador de necessidades especiais. São Paulo: Fiúza Editores, 2002.

SOUZA, C. M.A.; GITAHY, R. R.C. Acessibilidade das pessoas com deficiência física. Interfaces da Educação. Paranaíba, v.3, n.9, p.16-29, 2012.

VILLAROUCO, V. Desenho universal: caminhos da acessibilidade no Brasil. Pós: Revista do Programa de Pós-Graduação em Arquitetura e Urbanismo da FAUUSP, 01 June 2011, Vol.18(29), pp.290-292 